\title{
Expression of Personality through Avatars: Analysis of Effects of Gender and Race on Perceptions of Personality
}

\author{
Jennifer Cloud-Buckner, Michael Sellick, \\ Bhanuteja Sainathuni, Betty Yang, and Jennie Gallimore \\ Department of Biomedical, Industrial and Human Factors Engineering \\ Wright State University, Dayton, OH, 45435, USA \\ cloud.10@wright.edu
}

\begin{abstract}
Avatars and virtual agents are used in social, military, educational, medical, training, and other applications. Although there is a need to develop avatars with human-like characteristics, many applications include avatars based on stereotypes. Prabhala and Gallimore (2007) conducted research to develop collaborative computer agents with personality. Using the Big Five Factor Model of personality they investigated how people perceive personality based on actions, language, and behaviors of two voice-only computer agents in a simulation. However, these computer agents included no visual features in order to avoid stereotypes. The objective of the current research extends the work of Prabhala and Gallimore by investigating the effects of personality, race, and gender on perceived personality of avatars with animated faces. Results showed that subjects were able to distinguish the different personalities and race and gender significantly affected perceptions on a trait-by-trait basis.
\end{abstract}

Keywords: avatar, virtual agent, personality, Big Five Factor.

\section{Introduction}

Avatars are frequently used in social networking activities, educational contexts, and in medicine for training, telemedicine, collaboration among providers, rehabilitation, and group counseling [1-5]. For the military, avatars have been used to aid in various simulations, including the navigation of unmanned aerial vehicles. In the research of Prabhala and Gallimore [6], the avatar was actually represented by just a voice with personality rather than a visual representation. The voice guided the user through different navigation activities. However, in comparison of text-only, audio-only, audio-video, and audio-avatar chat contexts, the video-assisted and avatar-assisted chats resulted in higher ratings for subject attention than audio-only or text-only chats [7]. With the growing applications of avatars, it is important to note that the perception of avatars' personality and credibility can be affected by their appearance, behavior, language, and actions. The need for research and development for computer agents or avatars that more closely mimic human behaviors has been noted by many researchers $[6,11]$. Using the Big Five Factor model of personality, Prabhala and Gallimore (2007) found that people could perceive personality from avatars through their 
actions, language, and behavior [6]. Studies show that appearance, gender, and ethnicity can affect the user's reaction to the avatar [9-10]. Facial actions like head tilting, nodding, eye brow rising, and blinking are also used as visual cues in perceiving inherent personality [11].

\section{Methods}

\subsection{Objectives, Experimental Design, and Hypothesis}

The objective was to evaluate if people can perceive personality of computerized avatars based on actions, language, and behaviors and to determine if race and gender as represented in facial and voice features would affect perceptions. Independent variables are avatar's race (dark or white), gender (male or female), and personality (P1 or P2). These were arranged in a $2 \times 2 \times 2$ within-subject experiment. Data were collected on the subjects' ratings of 16 personality subtraits in the Big Five Factor Model and 4 subjective questions on a 10-point scale (1: trait is not very descriptive of avatar and 10: trait is very descriptive). The hypotheses are as follows: Hypothesis 1: There will be no significant differences in subject's subtrait ratings by personality. Hypothesis 2: Race and gender will not affect perception of personality.

\subsection{Subjects and Apparatus}

The subjects were recruited from Wright State University via e-mail and class announcements. Thirty-five subjects completed the study (16 female and 19 male). The subjects were not paid to participate and had the option to leave at any time. Test scenarios were presented with two 17-inch computer monitors, a Windows XPequipped computer, and headphones. Scripts were recorded with Audacity audio software from sourceforge.net, and avatars were developed in Haptek's PeoplePutty software. Statistical analysis was performed in JMP 7.0 and Microsoft Excel.

\subsection{Stimuli}

Avatar Appearance. Shown in Figure 1, avatars consisted of: 1) dark female, 2) white female, 3) dark male, 4) white male. Each used the same face structure.

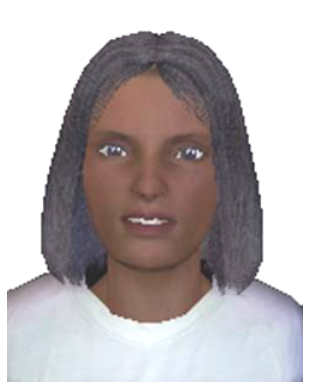

Dark female

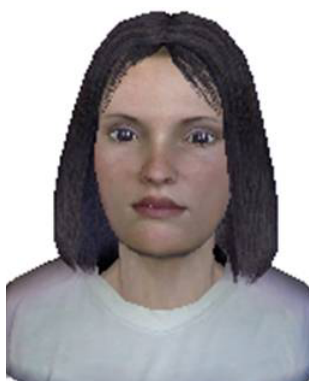

White female

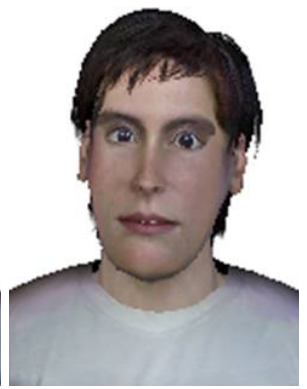

White male

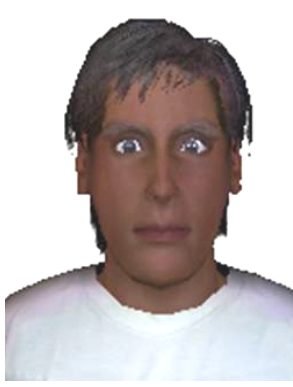

Dark male

Fig. 1. Avatar Appearance 
The only modifications to the basic face were changing skin color (dark or white), broadening of the male face, and lengthening of the females' hair.

Avatar Personality. The two personality levels were constructed to be completely opposite each other, around 16 of the 30 Big Five Factor model subtraits. These were selected for what could be emulated in scenarios; also, insignificant factors from [6] were omitted, such as artistic interests and liberalism. Traits emphasized in each personality type were given an expected rating of 10, shown in Tables 1 and 2. Personality 1 was designed to be friendly, outgoing, and self-sufficient with a high activity level and some anger. Personality 2 was designed to be introverted, self-conscious, cooperative, orderly, modest, disciplined, and sympathetic to others.

Table 1. Emphasized Traits and Actions, Language, and Behavior to Define Personality 1

\begin{tabular}{|l|l|l|}
\hline \multicolumn{1}{|c|}{ Subtrait } & $\begin{array}{c}\text { Expected } \\
\text { Rating }\end{array}$ & \multicolumn{1}{c|}{ Personality 1 } \\
\hline Friendliness & 10 & $\begin{array}{l}\text { Casual greeting, positive comments, friendly tone, } \\
\text { jokes, smiles with teeth showing and wide cheeks }\end{array}$ \\
\hline Gregariousness & 10 & $\begin{array}{l}\text { Is happy to see a crowd, talkative, likes activities with } \\
\text { crowds, makes eye contact }\end{array}$ \\
\hline Assertiveness & 10 & $\begin{array}{l}\text { No hesitation, expresses ideas openly, talkative, serves } \\
\text { as a leader of groups, makes eye contact }\end{array}$ \\
\hline Activity level & 10 & Involved in many activities, quick information pace \\
\hline Cooperation & 1 & Discusses confrontation about issue that angers them \\
\hline Modesty & 1 & $\begin{array}{l}\text { Talks about being superior to professors or other } \\
\text { students, brags about achievements }\end{array}$ \\
\hline Sympathy & 1 & Jokes about people being sick \\
\hline Self-efficacy & 10 & $\begin{array}{l}\text { Uses confident, self-focused phrases (e.g., confident } \\
\text { can do anything after graduation), never looks at notes }\end{array}$ \\
\hline Orderliness & 1 & $\begin{array}{l}\text { Might jump from point to point in their talk because } \\
\text { they don't know the order }\end{array}$ \\
\hline Self-discipline & 1 & Procrastinates on assignments / studying for tests \\
\hline Cautiousness & 1 & $\begin{array}{l}\text { Mentions campus security because "it's required," } \\
\text { mentions outdoor adventure activities }\end{array}$ \\
\hline Anxiety & 1 & Does not seem nervous about talking \\
\hline Anger & 10 & $\begin{array}{l}\text { Makes snide remarks; has a tirade about something on } \\
\text { campus (e.g., parking ticket, bad cafeteria food) }\end{array}$ \\
\hline Adventurousness & 10 & Bold opinions no matter what others think \\
\hline Intellect & 1 & Mention study abroad, outdoor adventure activities \\
\hline Prefers to people to ideas; does not like long puzzles \\
\hline
\end{tabular}


Table 2. Emphasized Traits and Actions, Language, and Behavior to Define Personality 2

\begin{tabular}{|l|l|l|}
\hline \multicolumn{1}{|c|}{ Subtrait } & $\begin{array}{c}\text { Expected } \\
\text { Rating }\end{array}$ & \multicolumn{1}{c|}{ Personality 2} \\
\hline Friendliness & 1 & Formal greeting, negative comments, Avoids eyes \\
\hline Gregariousness & 1 & Shy, avoids crowds, avoids eye contact \\
\hline Assertiveness & 1 & Hesitates while speaking, not talkative \\
\hline Activity level & 1 & Slower pace of info, involved in fewer activities \\
\hline Cooperation & 10 & $\begin{array}{l}\text { Avoids confrontation, offers individual help, talks } \\
\text { about helping on teams rather than leading them }\end{array}$ \\
\hline Modesty & 10 & $\begin{array}{l}\text { Does not brag about things, works hard in class but } \\
\text { does not take credit for being on top }\end{array}$ \\
\hline Sympathy & 10 & Offers extra guidance, condolences on problems \\
\hline Self-efficacy & 1 & $\begin{array}{l}\text { Has no control in their life (e.g., parents made them } \\
\text { go to that school); unsure about notes }\end{array}$ \\
\hline Orderliness & 10 & $\begin{array}{l}\text { Keeps organized schedule / notes for classes, regular } \\
\text { study times, meeting with professor on regular basis }\end{array}$ \\
\hline Self-discipline & 10 & Has regular study schedule ; finishes assignments \\
\hline Cautiousness & 10 & Talks about campus security, carrying pepper spray \\
\hline Anxiety & 10 & Apologizes for nervousness about talking \\
\hline Anger & 1 & Nice about everything, even when it is bad \\
\hline Self-consciousness & 10 & Shy about people; worried that they look stupid \\
\hline Adventurousness & 1 & Mention others doing study abroad, going outdoors \\
\hline Intellect & 10 & Describes solving puzzles; talks about ideas \\
\hline
\end{tabular}

A, L, B in Avatar Scripts. Each avatar script welcomed visitors and introduce a college campus as an online tour guide. The avatar personality was exhibited verbally through actions, language, and behavior (A, L, B) as well as tone of the avatar. The A, L, B for each trait are shown in Tables 1 and 2. Eight gender-neutral scripts were randomly assigned to the faces and each face had one script from P1 and P2. One female recorded all of the female scripts, and one male recorded all the male scripts.

Each script was 1.5 to 2 minutes long and followed the same order of items: initial facial expression, greeting, university name, purpose of the talk, why the speaker came to the school, the year the school began, number of students, academics including speaker's major, professors and classes, study abroad opportunities, facilities, dorms, security, clubs and organizations, and a conclusion.

\subsection{Procedure}

Each subject was randomly assigned to an "order code" that specified the random order in which the 8 scripts would be viewed. After each script, subjects filled in a 
randomized spreadsheet ratings questionnaire with their rating on a 1-10 scale of how well the subtrait described the avatar, and what A, L, B led to that rating. Each question included the definitions of the subtrait based on the Big Five Factor model, such as "Friendliness describes the quality of being amicable and having no enmity," This was repeated for all 8 scripts, and the entire process was generally 30-45 minutes. Subjects were also asked four subjective questions about the guide.

\section{Results}

\subsection{General Model and ANOVA Information}

Each of the 35 subjects answered 160 total ratings questions, resulting in 5600 data points. The ANOVA model included Personality, Race, Gender and Question (20) resulting in a $2 \times 2 \times 2 \times 20$ within-subject analysis. Question was included because each question addressed a different subtrait. Since traits like Anger and Friendliness are on opposite scales, performing an analysis across questions can result in an averaging of those traits. We are interested in evaluating how subjects perceived the different subtraits embedded in the personality. The Alpha level was set to 0.05 and resulted in 11 significant factors. To control for sphericity, a conservative Greenhouse-Geisser (GG) correction resulted in 7 significant factors. Significant interactions were analyzed with simple effects f-tests, and main effects were analyzed with Tukey-Kramer Honestly Significant Difference (Tukey HSD) tests.

\subsection{Interactions}

Gender x Personality $x$ Race (GxPxR). This interaction must be viewed by subtrait. Without the G-G correction the RxGxPxQ interaction was significant, and with the G$\mathrm{G}$ correction the p-value is 0.0692 . Given that the $\mathrm{G}-\mathrm{G}$ is conservative, we looked at the effects of $R$ and $G$ for each Personality and each subtrait and we find significant main effects of $\mathrm{R}, \mathrm{G}$ and $\mathrm{RxG}$ depending on the trait as indicated in Table 3.

Personality x Question (PxQ). PxQ was significant $(\mathrm{F}(1,34)=37.71, \mathrm{p}<0.0001)$. Simple effects F-tests show $\mathrm{P}$ is a significant factor for every $\mathrm{Q}$ except the one measuring Cooperation. Figures 2 and 3 illustrate the PxQ interaction for P1 and P2, respectively. The traits designed into $\mathrm{P} 1$ are rated as more descriptive for $\mathrm{P} 1$ than $\mathrm{P} 2$. For the traits designed into P2 there are two traits that are more descriptive for P1, Orderliness and Intellect. Cooperation was perceived equally for both P1 and P2.

Race x Question (RxQ) was significant $(\mathrm{F}(1,34)=.0211, \mathrm{p}=0.0211)$. When analyzed by each question, ratings for race were significantly different for the following traits: orderliness, anger, cooperation, self-consciousness, modesty, self-discipline, intellect, sympathy. For all of these traits, subjects gave higher ratings (more descriptive) when the race was Dark except on the subtrait Anger, in which case the rating was lower (less descriptive). Additionally, the Dark avatars received a significantly higher mean rating on the question asking subjects if they would be willing to trust information from that avatar. Figure 4 shows significant traits. 


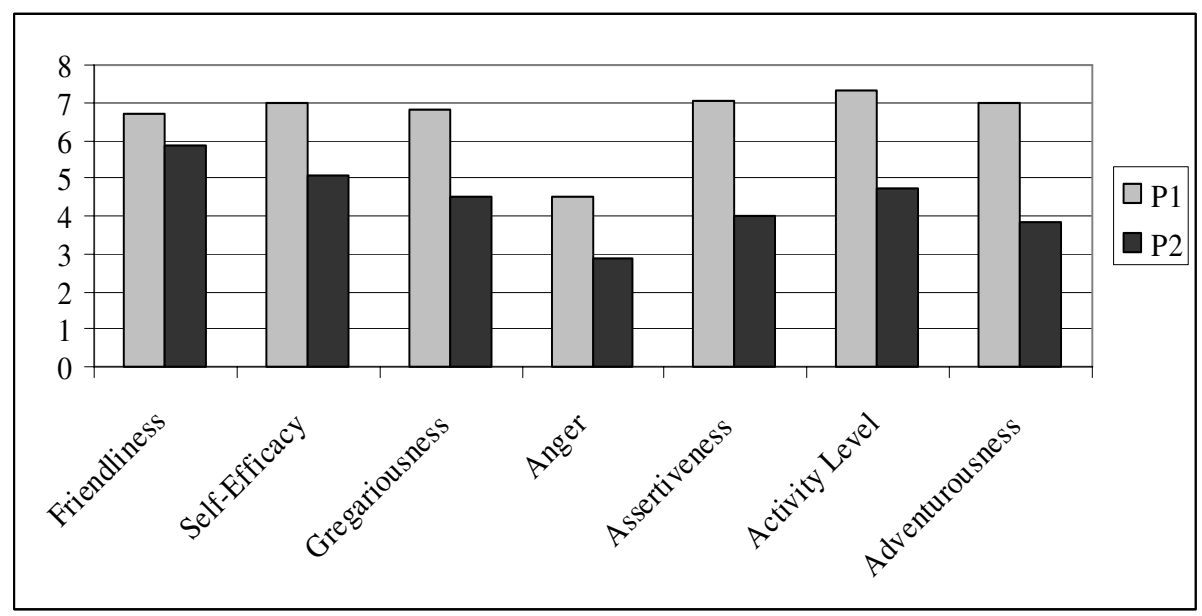

Fig. 2. Traits designed into $\mathrm{P} 1$ are rated on average as more descriptive than $\mathrm{P} 2$

Table 3. Instances of Significant Factors for Each Question, where $x$ indicates occurrence of statistical significance of that factor $(\mathrm{R}, \mathrm{G}, \mathrm{RxG})$ for a given personality and question

\begin{tabular}{|c|c|c|c|c|c|c|}
\hline & \multicolumn{3}{|c|}{ Personality 1} & \multicolumn{3}{|c|}{ Personality 2} \\
\hline & Race & Gender & $\mathbf{R} * \mathbf{G}$ & Race & Gender & $\mathbf{R} * \mathbf{G}$ \\
\hline Friendliness & & $\mathrm{x}$ & $\mathrm{x}$ & & & \\
\hline Self-Efficacy & & & & & & \\
\hline Anxiety & & & & & & \\
\hline Gregariousness & & & & & $\mathrm{x}$ & \\
\hline Orderliness & & & & $\mathrm{x}$ & & \\
\hline Anger & $\mathrm{x}$ & $\mathrm{x}$ & $\mathrm{x}$ & $\mathrm{x}$ & & \\
\hline Assertiveness & & & & & $\mathrm{x}$ & \\
\hline Activity Level & & & & & & \\
\hline Cooperation & $\mathrm{x}$ & $\mathrm{x}$ & & & $\mathrm{x}$ & \\
\hline Self Consciousness & $\mathrm{x}$ & $\mathrm{x}$ & & & $\mathrm{x}$ & $\mathrm{x}$ \\
\hline Adventurousness & & $\mathrm{x}$ & & & & \\
\hline Modesty & $\mathrm{x}$ & & & $\mathrm{x}$ & & \\
\hline Self-Discipline & $\mathrm{x}$ & & & $\mathrm{x}$ & $\mathrm{x}$ & $\mathrm{x}$ \\
\hline Intellect & $\mathrm{x}$ & & $\mathrm{x}$ & $\mathrm{x}$ & & \\
\hline Sympathy & $\mathrm{x}$ & $\mathrm{x}$ & & & & $\mathrm{x}$ \\
\hline Cautiousness & $\mathrm{x}$ & & & & & $\mathrm{x}$ \\
\hline Q: Willing to trust? & $\mathrm{x}$ & $\mathrm{x}$ & $\mathrm{x}$ & $\mathrm{x}$ & & $\mathrm{x}$ \\
\hline Q: Satisfied w/ tour guide? & & & $\mathrm{x}$ & & & \\
\hline Q: This guide for later tour? & $\mathrm{X}$ & & & $\mathrm{x}$ & & \\
\hline Q: School with this disposition? & $\mathrm{x}$ & & & & & \\
\hline $\begin{array}{ll} & \text { Total }\end{array}$ & 11 & 7 & 5 & 7 & 5 & 5 \\
\hline
\end{tabular}




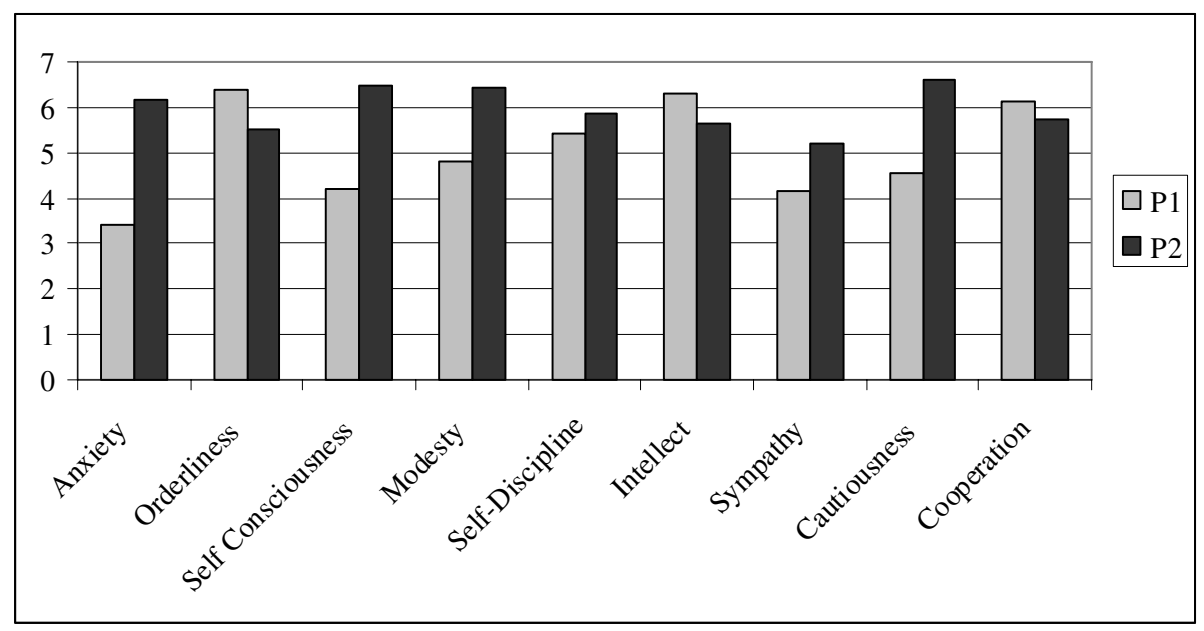

Fig. 3. Traits designed into $\mathrm{P} 2$ are more descriptive for $\mathrm{P} 2$ than $\mathrm{P} 1$ for 6 of the 9 traits

\subsection{Descriptions of Actions, Language, Behavior That Led to Ratings}

Out of 5600 rating points, 571 comments were provided from subjects. They centered on these areas: tour guide's direct quotes, guide's behaviors, tone of voice or accent, stuttering, pauses, forgetfulness, and lack of organization. Most comments referred to verbal rather than visual elements. Comments on appearance mentioned lack of eye contact, looking "boring," "comfortable" facial expressions, and head movement. Every script element except for school size was mentioned at least once in comments. Some elements had up to 15 comments. The script lines were specifically designed to represent certain personality traits, but those were not always interpreted as intended. For example, when one avatar mentioned living at home with parents, some subjects interpreted that as intelligent budgeting while others saw that as lack of self-efficacy.

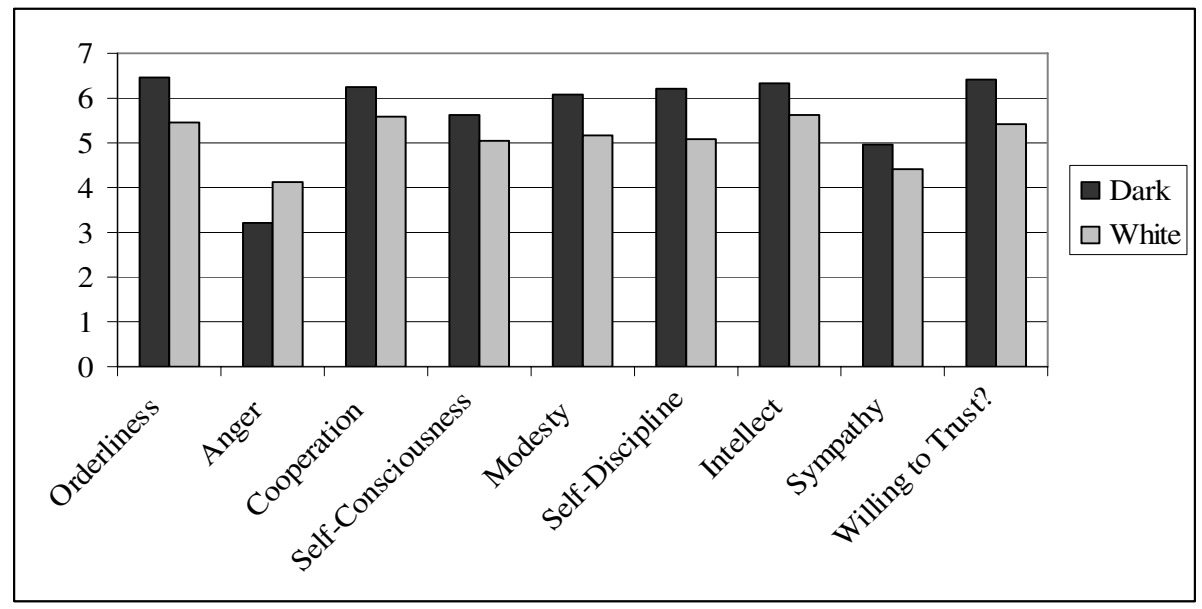

Fig. 4. Two-Way interaction of Race x Question (Significant questions only) 


\section{Discussion}

\subsection{General Conclusions on Hypotheses}

The results rejected the null hypothesis of no difference in subtrait ratings by Personality. The two avatar personalities were specifically designed to be different and the ratings indicate that subjects perceived differences in the personalities. These findings are similar to those of Prabhala and Gallimore (2007) who found that subjects could perceive differences in personality even without a face. P1 was rated higher (traits more descriptive) on all 7 traits specifically designed into it. For P2, only 6 of the 9 traits that were built into the personality were perceived as "more descriptive" than P1. Two traits were rated as being more descriptive in P1 than in P2 (Orderliness and Intellect). There was no significant difference in ratings for Cooperation between P1 and P2. The magnitude of differences in the mean ratings varied across traits. For example, the difference in means for friendliness between P1 and P2 is 0.85 , while the differences in all other traits built into P1 vary from 1.64 to 3.17. In P2, difference in mean ratings for self-discipline is only 0.47 , while the other significant traits range from .0 .67 to 2.79). It appears that traits for $\mathrm{P} 2$ are more difficult to model into the personalities. Traits that are related to emotion have larger differences (Anger and Anxiety). Adventurousness and activity level also has a larger differences, because scripts for P1 had notable sports and activity information, such as rock climbing or study abroad rather than P2's swimming laps or walking.

The null hypothesis that there would be no difference in ratings based on race and gender was rejected. We expected no differences, but race and gender of the avatar did play some role in perceptions of personality. For example, for P1 and P2, when there was a difference on Race, the dark skin had a higher rating for every item except anger. When there was a difference on Gender, in P1, the male had a higher score, but in P2, the women had a higher score. The interaction of RxG had mixed results across all subtraits. Overall, dark males had higher ratings on many personality traits except anger, which showed the lowest rating. It is difficult to understand the cause of these effects; we could not use race and gender as subject blocking variables so no comparison can be made between the subject's race or gender and their ratings for the avatars of different races. Approximately $75 \%$ of the subjects were white.

\subsection{Implications for Future Research}

The different ways that some script elements were interpreted by subjects indicates that future research should include a personality profile of the subject to see if the person's preferences affect their favorable ratings on other personality types. Additionally, implications of racial bias in the RxQ results mean that future studies should track the race of the subject to see how the person's race affects responses. Subjects should clearly understand that their answers are anonymously combined with others' so that no judgments are made on their individual racial preferences. Some comments mentioned voice tone and accent, so future research should consider using different human and computer-generated voices to address this, especially when non-native English speakers are involved. Personality can also affect interpretation of tone; in one study extroverts were more attracted to extroverted voices; similarly, introverts were more attracted to introverted voices [17]. 
The 571 comments about A, L, B showed that most comments referred to avatar verbal elements rather than visual appearance, possibly indicating that subjects' biases for avatar appearance were revealed only through ratings, not through the comments.

The scenario of avatars presenting a campus tour was a good vehicle to convey personality preferences. Differences between the schools were minimal but still conveyed some personality preferences of the avatars. In future studies, it would be interesting to see how different scenarios affect ratings. With a growing need for computer agents that resemble human behavior, this research confirms that personality can be both modeled and perceived and provides insight on how gender and race affect the perceptions of personality.

\section{References}

1. Kang, H.-S., Yang, H.-D.: The visual characteristics of avatars in computer-mediated communication: Comparison of internet relay chat and instant messenger as of 2003. Int. J. Hum.-Comput. St. 64(12), 1173-1183 (2006)

2. Gorini, A., Gaggioli, A., Vigna, C., Riva, G.: A second life for eHealth: Prospects for the use of 3-D virtual worlds in clinical psychology. J. Med. Internet Res. 10(3), e21 (2008)

3. Monahan, T., McArdle, G., Bertolotto, M.: Virtual reality for collaborative e-learning. Computers 50(4), 1339 (2008)

4. Heinrichs, W., Youngblood, P., Harter, P., Dev, P.: Simulation for team training and assessment: Case studies of online training with virtual worlds. World J. Surg. 32(2), 161170 (2008)

5. Hilty, D., Alverson, D., Alpert, J., Tong, L., Sagduyu, K., Boland, R.: Virtual reality, telemedicine, web and data processing innovations in medical and psychiatric education and clinical care. Acad. Psychiatr. 30(6), 528-533 (2006)

6. Prabhala, S.V., Gallimore, J.J.: Designing computer agents with personality to improve human-machine collaboration in complex systems. Wright St. Univ. (2007)

7. Bente, G., Rüggenberg, S., Krämer, N.C., Eschenburg, F.: Avatar-mediated networking: Increasing social presence and interpersonal trust in net-based collaborations. Hum. Commun. Res. 34(2), 287-318 (2008)

8. Rizzo, P., Veloso, M., Miceli, M., Cesta, A.: Personality-Driven Social Behaviors in Believable Agents. In: Proceedings of the AAAI Fall Symposium on Socially Intelligent Agents (1997)

9. Nasoz, F., Lisetti, C.L.: MAUI avatars: Mirroring the user's sensed emptions via expressive multi-ethnic facial avatars. J. Visual Lang. Comput. 17, 430-444 (2006)

10. Masuda, T., Ellsworth, P., Mesquita, B., Leu, J., Tanida, S., De Veerdonk, E.: Placing the face in context: Cultural differences in the perception of facial emotion. J. Pers. Soc. Psych. 94(3), 365-381 (2008)

11. Arya, A., Jefferies, L.N., Enns, J.T., DiPaola, S.: Facial actions as visual cues for personality. Comput. Animat. Virt. W 17(3-4), 371-382 (2006)

12. Lee, K., Nass, C.: Social-psychological origins of feelings of presence: Creating social presence with machine-generated voices. Media Psychol. 7(1), 31-45 (2005) 